\title{
Correction to: Convection-permitting regional climate simulation of warm-season precipitation over Eastern China
}

\author{
Yuxing Yun ${ }^{1}\left(\mathbb{D} \cdot\right.$ Changhai Liu $^{2} \cdot$ Yali Luo ${ }^{1,4} \cdot$ Xudong Liang $^{1} \cdot$ Ling Huang $^{3} \cdot$ Fei Chen $^{2} \cdot$ Roy Rasmmusen $^{2}$
}

Published online: 20 February 2020

(c) The Author(s) 2020

\section{Correction to: Climate Dynamics \\ https://doi.org/10.1007/s00382-019-05070-y}

The article Convection-permitting regional climate simulation of warm-season precipitation over Eastern China, written by Yuxing Yun, Changhai Liu, Yali Luo, Xudong Liang, Ling Huang, Fei Chen, Roy Rasmmusen was originally published electronically on the publisher's internet portal (currently SpringerLink) on 6 December 2019 without open access.

With the author(s)' decision to opt for Open Choice the copyright of the article changed on 25 February 2020 to $($ ) The Author(s) 2020 and the article is forthwith distributed under the terms of the Creative Commons Attribution 4.0 International License (http://creativecommons.org/licenses/ by/4.0/), which permits use, duplication, adaptation, distribution and reproduction in any medium or format, as long as you give appropriate credit to the original author(s) and the source, provide a link to the Creative Commons license and indicate if changes were made.

The original article was corrected.

The original article can be found online at https://doi.org/10.1007/ s00382-019-05070-y.

Yuxing Yun

yunyx@cma.gov.cn

$\triangle$ Yali Luo

ylluo@cma.gov.cn

1 State Key Laboratory of Severe Weather, Chinese Academy of Meteorological Sciences, Beijing, China

2 National Center for Atmospheric Research, Boulder, USA

3 Guangzhou Institute of Tropical and Marine Meteorology, Guangzhou, China

4 Innovation Center on Forecast and Evaluation of Meteorological Disasters, Nanjing University of Information Science and Technology, Nanjing, China
Publisher's Note Springer Nature remains neutral with regard to jurisdictional claims in published maps and institutional affiliations. 